NBER WORKING PAPER SER IES

THE IMPACT OF THE RUNAWAY OFF ICE ON UNION CERTIF ICATION ELECTIONS

IN CLERICAL UNITS

\author{
Beatrice J. Freiberg \\ William T. Dickens
}

Working Paper No. 1693

\author{
NATIONAL BUREAU OF ECONOMIC RESEARCH \\ 1050 Massachusetts Avenue \\ Cambridge, MA 02138 \\ August 1985
}

The authors thank Dean Francis and John Montoya of the Oakland, California Regional Office of the NLRB for making available the data used in this study. The authors al so greatfully acknowledge the help of Mary Ann Massenburg, Barbara Baran, Kay Eisenhower, John Bowers, Phil Shapira, Lucas Guttentag, Suzy Teegarden, Rome Aloise, Marcella Farinha, Jack McLaughl in, and many other union organizers and researchers who gave generously of their time. Finally, the authors al so thank Phil ip Bokovoy for research assistance and the University of Cal ifornia Presidential Fellowship Committee and the Institute of Industrial Relations for generous research support. The research reported here is part of the NBER's research program in Labor Studies. Any opinions expressed are those of the authors and not those of the National Bureau of Economic Research. 
NBER Working Paper \# 1693

August 1985

\section{The Impact of the Runaway office on Union Certification Elections in Clerical Units}

\section{ABSTRACT}

The law prohibits firms from moving work to avoid unionization. Still, many employees fear that joining a union may cost them their jobs. This paper assesses the impact of that fear on how clerical workers vote in union certification elections. Two data sets were collected and analyzed for this purpose, and three measures of the firms' ability to relocate office work were developed.

Clerical workers in offices that were judged to be easier to relocate were found to be more likely to report that the fear of job loss was important to their voting decision. Those who voted against the union were most likely to report that the fear that they would lose their jobs was a significant consideration. Further, workers in units judged to be most easily relocated were found to have a 7 to $30 \%$ lower probability of voting union than those who were in less mobile jobs.

Beatrice J. Freiberg Office of the New York City Comptroller Municipal Bldg. Room 526

New York, NY 10007 (212) $566-3770$
William T. Dickens Department of Economics University of California Berkeley, CA 94720 (415) 642-4308 
"I've worked for Mutual Insurance for the past ten years doing clerical work."

"Are the clerical workers unionized at Mutual Insurance?"

"Oh, no. We don't want a union."

"Why not?"

"Job security. When the union won at Blue Shield, the employer moved their jobs. The union couldn't hold on to their jobs. We don't want a union. We prefer to have our jobs."

Conversation with a San Francisco clerical worker, June 1983

In 1972 Office and Professional Employees Union (OPEU) organized 1700 keypunch and data processing employees at Blue Shield Insurance Company, San Francisco. Eleven years later, only one hundred jobs were left. In 1974 the employer transferred 500-600 jobs to a nonunion office in San Diego. Later, the union lost an organizing drive there. In 1981, the largely minority-female work force struck Blue Shield. During the five-month strike that ensued, Blue Shield relocated about 450 jobs to six nonunion offices. The work, which was done on computer terminals, could be easily transferred electronically to the other offices. Finally, more than 400 jobs were moved to three remote small-town offices in 1983. "Now, wherever there's an organizing drive, employers use what happened at Blue Shield as a warning to their workers," said a former Blue Shield employee. "They tell them, 'Oh sure, you want to vote for the union. Well, let me tell you what the union did for the employees in San Francisco--lost their jobs." 1

Labor law places few restrictions on a unionized employer's right to relocate work. Prior to the 1984 National Labor Relations Board (NLRB) 
decision, ${ }^{2}$ the only reasons for which an employer could not relocate union jobs were 1) the cost of labor, 2) to avoid a union organizing attempt, or 3) to rid a company of a union. Under the new ruling, labor costs may justify moving an operation. If the union succeeds in raising workers' wages, the company has a legal excuse for relocating the work.

Companies with organized office workers have taken advantage of the allowances the law makes and have left the union behind. Blue Shield in San Francisco moved 1600 organized clerical jobs to nine nonunion offices; Consumer's Distributing Company relocated its Western Regional office with 50 organized clerical workers along with its other operations to Reno, Nevada; Pacific InterMountain Express, a trucking company in Oakland, California, moved its entire operations, including 100 organized clerical jobs, to Florida; and O.N.C. Trucking Company, owned by Rocor International, expanded and moved 130 union clerical jobs to Kansas City, Missouri. In the course of our research, we encountered 22 cases of runaway union offices in the San Francisco Bay Area between 1973 and 1983. This list is by no means exhaustive.

In the past, office work was as moveable as the company of which it was a part. But with advances in microprocessor technology and telecommunications, office work is easy and inexpensive to move. Employers can now relocate office work electronically. A 1983 Wall Street Journal headline read, "Now we can move office work offshore to enhance output." 3 According to the article, satellite technology and falling prices in hardware, transmission costs, and earth stations make it cost effective for large corporations, particularly in banking, insurance and publishing, to move data entry and word processing jobs to remote locations. 
One consequence of the ease with which office jobs can be moved may be a heightened sense of job insecurity among office workers. Job security -once a compelling reason to vote for the union -- may ironically have become a potent management threat, helping to prevent unionization.

If the fear of relocation is a significant concern, then clerical workers with mobile jobs should vote against unionization more often than clerical workers with jobs that cannot be moved, all other things held equal. This paper considers the hypothesis that the ease with which jobs may be moved (job mobility) has a significantly negative impact on the percent of workers voting union in certification elections. To do so, the voting behavior of clerical workers in 101 union certification elections (UCEs) was analyzed. We find that workers in the most mobile offices are 7 to 30 percent less likely to vote union than those in the least mobile jobs, depending on the measure of mobility used and the specification used to estimate the effect. These results may help explain why union organizers believe that clerical organizing has been most successful in not-for-profit organizations and the public sector, and less successful in finance, insurance and real estate companies. ${ }^{4}$ To the extent that jobs in not-for-profit organizations and the public sector are largely immobile, they will be earier to organize.

The next section discusses the data collected to analyze the impact of the fear of relocation on voting in UCEs. The section following discusses the measures of job mobility developed for this study. We then consider whether workers in firms rated to be mobile by our criteria perceive their jobs to be mobile and whether that was an important consideration in their decision to vote union. Finally, we present the analysis of the voting 
data. The conclusion reviews the findings and considers their relevance for explaining recent trends in UCE success rates and for labor law.

Data

In order to determine the impact of office mobility, results from 101 UCEs involving only office workers were gathered. The elections were held in the Oakland and San Francisco regional NLRB districts between 1971 and 1983. Eighty-nine of these UCEs were randomly selected from the "closed case" files of the Oakland regional office of the NLRB, and twelve from the same files at the San Francisco NLRB regional office. The selection process involved searching 12,000 index cards of closed cases and singling out only those cases where an election in a clerical unit had been held. From all the index cards a random sample of 101 clerical elections was chosen. Clerical units were defined to be those including one or more of the following jobs: office-clericals, data processors, switchboard operators, secretaries, PBX operators, plant clericals, warehouse clericals, receptionists, reservationists, cashiers, desk clerks, customer service representatives, key entry operators, dispatchers, and telephone operators.

There were 4,652 clerical workers involved in the 101 union elections. The union won $61 \%$ of the elections, and the company won the remaining $39 \%$. Fifty-seven percent of all workers voted for the union. Although the percentage of union victories in the sample is substantially greater than the national or the California average for union wins in any year for which data are available, ${ }^{5}$ there is no reason to expect that the percentage of union wins in clerical units should be the same as for other types of units. For example, win rates differ greatly by industry. Also, because 
of the difficulty in organizing clerical units, unions may only take on those cases which are more likely to win.

In order to analyze the effect of mobility as a determinant of election results, information on other variables known to influence outcomes of union elections was obtained so that their effects could be controlled for. Some of the background information on each election was gathered from the NLRB election files: the election date, the company name and location, the industry, the union name and local number, and the size and job description of the office unit. To obtain the rest of the data, the union organizer or local president involved in each election was interviewed and asked: the number of other employees at each location, whether these employees were organized, the number of other organized and unorganized company locations, the degree of management resistance during the organizing campaign, ${ }^{6}$ how easy it would be for the company to relocate, a detailed description of the office work, and the gender and ethnicity of the unit.

Measuring Mobility

Measuring the mobility of clerical jobs poses a difficult problem. Little research has been done on what types of firms are most likely to relocate. Therefore, in order to distinguish between the mobile jobs and immobile jobs in our sample, methods to measure the mobility of office work had to be developed. Three different methods were used. Each has advantages and drawbacks. The evidence from the three measures is complimentary and, together, much stronger than using any one by itself.

The first method used to determine the mobility of election units was to survey the organizers involved in each election. Each described the 
type of work the clericals performed and rated the work as mobile, somewhat mobile, or immobile. Since the organizers have detailed information about the company and its ability to relocate jobs, and since they knew which offices they had previously organized had moved and which had not, they should be qualified to make an informed assessment.

The major disadvantage of this method is that the organizers are not unbiased judges. Organizers know the outcome of the elections and whether the work was relocated. They might be expected to exaggerate the mobility in elections they lost to justify the outcome, thus causing a spurious correlation between mobility and election losses. Also, a few of the organizers were unfamiliar with office work and may not be expert judges of mobility.

The second method used for defining the clerical units as mobile or not involved employing an expert on firm's locational choices. Our expert was Barbara Baran, a doctoral candidate in the University of California, Berkeley's Department of City and Regional Planning, who is writing a thesis on how firms decide where to locate office jobs. The organizers mentioned above were also asked to list the criteria they thought important in determining mobility. Ms. Baran was given information on the following 22 characteristics, which were the ones most frequently mentioned.

1) Do the office workers do general office work? (a variety of clerical tasks which need to be done on site, excluding computer work)

2) Do the office workers do work for more than one office?

3) Do the office workers work with computers?

4) Are the office workers plant clericals? (Clericals who track inventory and whose jobs could be moved only if the plant were moved.) 
5) Do the office workers work in a health care facility?

6) Do the office workers work for a utility?

7) Do the office workers do mainly phone work?

8) Do the office workers work on a switchboard?

9) Do the office workers work with customers on site?

10) Number of clericals in the election unit.

11) Number of workers at site.

12) Year of the election.

13) Are there other workers organized at site?

14) Are other workers at site also voting in an election?

15) Are other company offices organized?

16) Are all other company offices organized?

17) Number of other company offices.

18) Is this a family-owned business?

19) Industry.

20) Population of city or town.

21) Union involved in the election.

22) Unique features of unit relevant to mobility of jobs. For example, brief, detailed job descriptions.

She rated the clerical units as mobile, somewhat mobile, or immobile, based on the above information. Besides the obvious advantage of using an expert on office mobility to decide each firm's potential to relocate, the other advantage of this method is that Ms. Baran did not know the results of the union elections or whether any firms moved. However, this measure has a drawback in that it was based on less information than the organizers'. 
For our third measure we constructed an index of mobility. The index incorporated 15 of the 22 mobility determinants used by the expert judge's analysis. Based on discussions with organizers, and other experts familiar with office work and runaway jobs, the factors were assigned weights according to their relative importance in determining the mobility of office work. Positive points were awarded to those characteristics that were associated with immobility and negative points were given for those that are associated with mobility.

\section{TABLE 1 ABOUT HERE}

We began by assuming that a firm with none of these characteristics would be mobile ( -5 points). Points were added and subtracted from these. After the adding and subtracting was done, firms with negative point totals were rated as mobile.

The advantages of the index of mobility are that it is systematic and somewhat objective. ${ }^{7}$ Major disadvantages of this measure are that the system uses only a limited amount of information and has no flexibility to deal with unique cases.

\section{Validating the Mobility Measures}

Do office workers know and care about mobility? If the theory is correct that the fear of relocation makes office workers less likely to vote for unionization, then office workers must be aware of the mobility of their work. In order to document this awareness, a questionnaire was developed to test whether relocation is more of a concern among office workers with mobile jobs than among workers with immobile jobs. 
The questionnaire was given to clerical workers at five locations where UCEs had recently been held. The five elections were the only recent ones in the Bay Area where we were able to gain access to the workers. (A copy of the questionnaire is provided in Appendix 1.) The questionnaire asked the office workers to rate the importance of ten factors in their decisions to vote for or against the union. They could rate the factors as very important ( 1 point), somewhat important (2 points), not too important ( 3 points) and not at all important ( 4 points). The only response on the questionnaire of interest was the rating given to the item "the concern that your employer may have your job done at a different location, if the union won."

The first group of office workers who answered the questionnaire worked for a major airline as phone reservationists. Applying the mobility criteria from table 1 , these jobs are considered mobile. Beginning with -5 points and adjusting for the applicable categories:

(6) there were other organized workers (2 points);

(11) the ratio of clerical work to nonclerical work was $\geqq 66 \%$ ( -4 points);

(12) the office workers worked entirely with computers ( -4 points); and

(15) the sole function of the office was phone work ( -2 points);

we arrive at a score of -13 points. The union certification election at this airline company lost. The average response on the question about the importance of fear of job loss was 3.50, halfway between not too important and not at all important.

The next group of workers who filled out the questionnaire worked for a trucking company and their jobs were also determined to be mobile by the criteria: (1) General office work (5 points); (6) other organized workers (2 points); (11) ratio of clerical work to nonclerical is greater than or 
equal to $66 \%$ ( -4 points); and (13) some of the office work is done on computers ( -2 points) -- or -4 points overall. The UCE lost here, too. The average response of the clericals at the moving company was 2.5 , halfway between not too important and somewhat important.

The third group of workers, employed by a retail food store, were called immobile by the criteria. They were ( -5 to begin) (2) plant clericals ( 10 points), (9) the percentage of clericals was less than $10 \%$ ( 4 points), and (6) there were other organized workers (2 points) -- for 11 points. The UCE held here won.

According to the criteria, the plant clericals were the most immobile group of workers. Their average response to letter D was 3.86 out of a possible four points. More than four-fifths of those responding said that the possibility of job loss was not at all important in their decision.

The fourth group who filled out the questionnaire were the office clericals for the same retail food store. The union was certified here, too. The criteria determined the work to be immobile because (begin with -5) (1) they did general office work (5 points); (6) other organized workers (2 points); (9) percentage of clericals to nonclericals was less than $10 \%$ ( 4 points); and (12) all the clericals worked with computers ( -4 points); this total is two points.

The average response of the office-clericals (the least immobile of the immobile groups) was 3.62. More than three-fifths of those responding said that the possibility of job loss was not at all important in their decision.

The criteria also defined the last group as immobile. They worked for a Cable T.V. company and voted for representation. They did (begin with -5) (1) general office work (5 points); (6) worked with organized workers 
( 2 points); (9) the percentage of clericals to nonclericals was less than $10 \%$ ( 4 points); and (13) some of the clericals worked with computers ( -2 points). This gave the unit a total of four points. The workers here voted to certify the union. The average response that these clericals gave to the importance of job relocation was 3.75 . Over three fourths of the clericals reported that job loss was not an important consideration in their decision.

The ratings that the five groups of workers gave to the importance of the fear of job relocation were consistent with the mobility criteria; the clericals with the mobile jobs rated the threat as more important. The average rating for the mobile workers was 3.32 and the average rating for immobile workers was 3.71 (with one meaning very important and four least important). The difference of these means is statistically significant at the .05 level using a one-tail $\mathrm{T}$ test.

These results indicate that workers in mobile jobs do perceive and care about the possibility of job mobility. Although on average workers rated this factor somewhere between not too important and not at all important, company voters in the two mobile units viewed the issue as being "not too important" to "somewhat important" on average. 8 Some saw it as "very important." Further, workers in the two mobile firms viewed the issue as more important, on average, than those in the units judged to be immobile.

Finally, the fact that in each election judged to be immobile the union won, and in every case union voters saw mobility as a less important issue than those who voted against certification, suggests the importance of job mobility in determining the outcome of certification elections. The next section considers this question in more detail. 
Analysis of the Voting Data

Table 2 presents the one-way analysis of variances for the percent of office workers voting for the union, broken down into mobile and immobile groups using each of the three mobility measures. In all cases, the mobility effect is in the anticipated direction -- lowering the probability of voting union. The magnitudes are roughly the same for the three measures and workers in the most mobile units are statistically significantly less likely to vote for the union. The F tests reject the hypothesis at the .05 level for both the organizers and the mobility index ratings. The expert judge's rating rejects the hypothesis at the 0.15 leve1.

While these results support the hypothesis that more mobile clerical units are more likely to vote against unionization, they are not conclusive. The one-way analysis of variance provides no controls for other factors which may be influencing election outcomes. Many factors which determine mobility may have a direct effect on the election outcomes as well. To account for these effects we used a statistical procedure with multiple control variables. The procedure allows for the fact that the percent voting union in an election is a limited dependent variable. It also allows for possible heteroskedasticity in the error term in the equation predicting the proportion voting union, which is caused by the variation in the number of people taking part in each election. The procedure is a modified version of Haldane's minimum $\chi^{2}$ logit proposed by Dickens ${ }^{9}$ (see Appendix 2 for a description).

Initially, all the control variables listed in table 3 were entered into the analysis and those with $t<1$ were removed (except for the mobility variables). Overall, the coefficient values for mobility either 
did not change or became smaller as variables were removed. However, the standard errors becaine smaller as the degrees of freedom increased.

Table 4 shows the results for the minimum $x^{2}$ logit analysis. The first column presents the coefficients of the mobility dummy variables. The second column presents the approximate impact of mobility on the proportion of workers voting for certification, and the third column presents the results of the $F$ tests for joint significance of each set of mobility measures.

The first set of results does not include controls for management resistance. In this case the signs and relative sizes of the coefficients are all as would be expected except for the units organizers rated as somewhat mobile. There the coefficient is slightly positive but is far from statistically significant. For both the expert judge's ratings and the mobility index, the mobile units are statistically significantly less likely to vote union and the impact on the probability of voting union is nearly the same as for the one-way analysis of variance.

Previous work on the determinants of voting in union certification elections suggests the importance of management resistance. ${ }^{10}$ It is possible that mobility is not responsible for reducing the probability of workers voting union. Rather, management resistance might be stronger in the mobile firms. The problem with controlling for management resistance is that it is endogenous; in the companies where, for reasons we do not observe, the organizing drive is weak, management's anti-union campaign does not need to be as intense to win. Strong union organizing drives may give rise to intense management efforts or no effort at all. Therefore, the results including management resistance variables should be interpreted with caution. 
With management resistance included, the coefficients all have the anticipated signs and relative magnitudes. In addition, their sizes do not change much. However, only the mobility index measure is still statistically significant. This may mean that the management resistance and mobility effects are substitutes for each other; when one effect is present, the other does not matter. Therefore the impact of mobility on elections should be examined where management resistance was negligible. The third section of table 4 presents these results. Here, the coefficients all have the anticipated signs; three out of five are statistically significant. The only peculiar result is that the effect of "somewhat mobile" is greater than "mobile" in the expert judge's result. However, the hypothesis that the effect of "mobile" is greater than "somewhat mobile" cannot be rejected. In all three cases the impact of mobility is large and, for the most mobile units, statistically significant.

The pattern of results is strongly consistent with the hypothesis that the mobility of office work influences voting in union certification elections. The effect was to reduce the percent voting for certification by $7.5-30 \%$, with most estimates around $15 \%$. In this sample of clerical elections, as in most UCEs, the elections are close so that a $1 \%$ decrease in the probability of voting union translates into roughly a $2 \%$ drop in the probability of a union victory. Thus, mobile office units appear to be $15-60 \%$ less likely to certify a union. 
Conclusion

We have examined the role of job mobility in influencing the outcome of union certification elections. To determine whether workers in more mobile jobs perceived mobility to be an important problem, we constructed and distributed a questionnaire to workers who took part in recent certification elections. Workers in the two units judged to be mobile, on average, felt that the fear of job loss was a more significant factor in their voting decision than the workers in the three immobile units. Also, those who voted against certification were more likely to report that mobility was a significant factor in their decision.

To determine the impact of mobility on voting, data was collected on 101 clerical unit certification elections which took place in Central and Northern California between 1971 and 1983. Three measures of office mobility were developed. The analysis of this data suggests that clerical workers in potentially mobile jobs are considerably less likely to vote union than those in immobile jobs.

These results can help explain why union organizers believe clerical organizing has been much more successful in the public sector and in not-for-profit firms than in large private-sector firms. To the extent that clerical units in private-sector firms are easier to move, they will be harder to organize. Additionally, if other types of workers are similarly fearful that unionization will result in job loss and if the claims by some authors that job relocation has been taking place more often in recent years are true, ${ }^{11}$ these results may also help explain the long-run decline in union success in organizing new workers. A recent Wall Street Journal article describes how Ingersoll-Rand has reduced the percent of its work force that is union by $30 \%$. In part this has been done by 
shutting down union plants. ${ }^{12}$ The article also describes the effect of this on how workers vote in union representation elections at Ingersol1-Rand. At least according to union leaders interviewed by the article's author, the fear of plant shutdowns was a major reason why workers voted against unions in several elections. If this pattern of aggressive union resistance is typical -- as the article suggests -- our results may also help explain the decline of union density in manufacturing.

Finally, to the extent that it is the goal of U.S. labor law to protect workers from employer coercion in choosing whether or not to be represented by a union, the law is failing -- at least for clerical workers. Our evidence strongly suggests that many workers are voting against unions not because they would prefer no representation but because they fear that if they choose representation they will lose their jobs. 


\section{Footnotes}

1. Conversation, 1983.

2. N.L.R.B. "Milwaukee Spring II," cited in Labor Relations Reference Manual (Bureau of National Affairs: Washington, D.C.), Vol. 115, pp. $1065-75$ (1984).

3. Kevin P. Powers, "Now We Can Move Office Work Offshore to Enhance Output," Wall Street Journal, June 9, 1983.

4. Based on conversations with 60 union organizers in 1983.

5. Annual Reports of the National Labor Relations Board for 1971 to 1981. The board has not published statistics for 1982 and 1983 yet.

6. The union representative was asked to describe the company anti-union campaign. From their descriptions, campaigns that included management consultants, firings, illegal threats, unfair labor practices, or at least a five-month delay were defined as "intense." Campaigns where the employer conducted an anti-union campaign without the assistance of an employee relations consulting or law firm were considered "moderate." "Low key" campaigns were ones that involved little or no active management resistance. In the seventeen cases where the union representative did not know the information about the campaign, the decision about the degree of management resistance was based on information from the NLRB files. For an "intense" rating, the election had to have at least two of the following: management labor lawyers, charges of unfair labor practices, or substantial delays. If the election had only one of the above, it was rated as "moderate." The "low key campaigns" were the ones which had none of the above 
conditions and had the election within three months after the petition was filed.

7. We cannot claim that the index is completely objective, since we were familiar with the results and characteristics of the elections when we constructed it. While no conscious effort was made to modify the index on the basis of the election results, the index cannot be considered experimentally blind to the outcomes.

8. The average score for all company voters was 2.90 compared to an average of 3.74 for those who voted union.

9. William T. Dickens, "Error Components in Grouped Data: Why Its Never Worth Weighting," NBER Technical Working Paper No. 43 (April 1985).

10. See Richard B. Freeman and James L. Medoff, What Do Unions Do?, Basic Books: New York, 1984, pp. 230-239, for a review of the literature on the impact of management resistance.

11. Barry Bluestone and Bennett Harrison, The De-Industrialization of America: Plant Closings, Community Abandonment and the Dismantling of Basic Industry. New York: Basic Books, 1982.

12. David Wessell, "Fighting off Unions, Ingersoll-Rand Uses Wide Range of Tactics, It Moves Plants, Drops Lines and Wins Worker Votes," The Wall Street Journal, June 13, 1985, p. 1. 
Table 1

Mobility Index

Points

At start

1. General office work

a variety of clerical tasks which need to be done on site

in order for the location to function (no computer work)...... 5

2. Inventory work; plant clericals (no computer work) ......... 10

3. Utility clericais........................... 10

4. Local or family ownership of a single operation........... 10

5. No other offices............................ 4

6. Other workers at plant or office are organized........... 2

7. No other unorganized locations.................... 3

8. Less than 3 other unorganized locations................ 2

9. Ratio of clerical workers to nonclerical workers at plant or

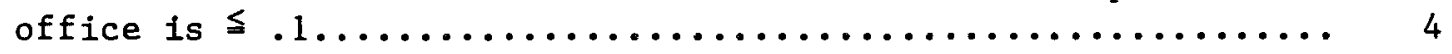

10. Office workers work with customers at the location.......... 10

11. Ratio of clerical workers to nonclerical workers at plant or

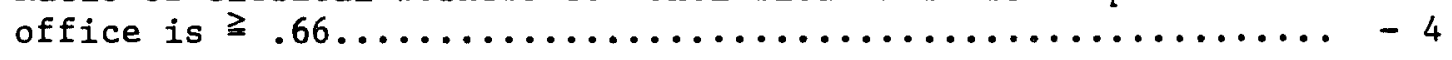

12. Office workers work entirely with computers............. 4

13. Some of the office work is done on computers............ - 2

14. The office workers do work for at least two of the company's

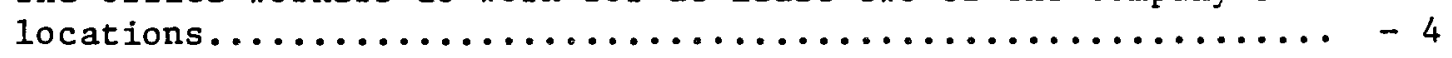

15. The sole function of the office is phone work............ - 2

Units with point totals $\geqq 0$ are assumed to be immobile. Those with negative point totals were assumed to be mobile. 
Table 2

One-Way Analysis of Variance of Percent of Workers Voting Union

$\begin{array}{ccc}\text { Mobility Measure } & \begin{array}{c}\text { Voting } \\ \text { Union }\end{array} & \begin{array}{c}\text { Difference } \\ \text { Between Mobile } \\ \text { and Not Mobile }\end{array}\end{array}$

Mobility Measure

Organizer's

Judgment :

Not Mobile

Somewhat Mobile

Mobile

Expert's
Judgment:

Not Mobile

Somewhat Mobile

Mobile

$62.6 \%$

$54.1 \%$

$45.9 \%$

$-8.5 \%$

$-16.7 \% *$

$8.2 \%$

$9.3 \%$

$6.4 \%$

$6.4 \%$

Standard Error for

Difference Between

Category and Not

Mobile
F-Test of Joint Significance

Mobility Index:

Not Mobile

$63.3 \%$

Mobile

$51.2 \%$

$-12.2 \% *$

$5.9 \%$

significant at .05 level

significant

.15 level

significant at .05 level

\footnotetext{
significant at .05 level *

.01 level **
}

in one-tail test 
Table 3

Control Variables Included in First Analysis

Composition of Unit:

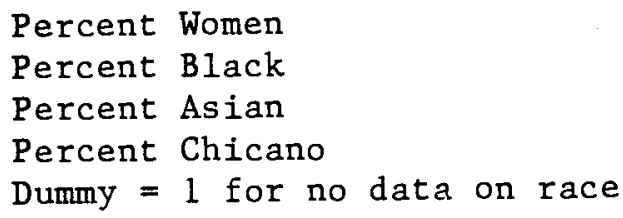

Year election was held

Number of workers employed at this site

Number of workers in unit

Percent of work force at site doing clerical work

Union Dummies:

Teamsters

SEIU

OPEU

ILWU

CWA

(left out category is other)

Industry Dummies:

Cannery

Manufacturing

Trucking and Warehousing

Communications

Wholesale and Retail

Business Services

Health Care

Utility

(left out category is FIRE)

Dummy $=1$ if business has no other locations.

Dummy $=1$ if business has more than 10 other locations.

Dummy = 1 if some other workers at site are organized.

Dummy $=1$ if some work is computer work.

Dummy $=1$ if clericals do work for other offices.

Dummy $=1$ if clericals do general office work.

Dummy $=1$ if clericals do inventory work.

Dummy = 1 if clericals deal with customers in person.

Dummy $=1$ if clericals do only computer work.

Dummy $=1$ if clericals do phone work.

Dummy $=1$ if clericals operate a switch board.

Dummy $=1$ if firm is family owned. 
Table 4

Minimum $x^{2}$ Logit Transformation of Fraction Voting Union

Regressed on Mobility Measures and Controls

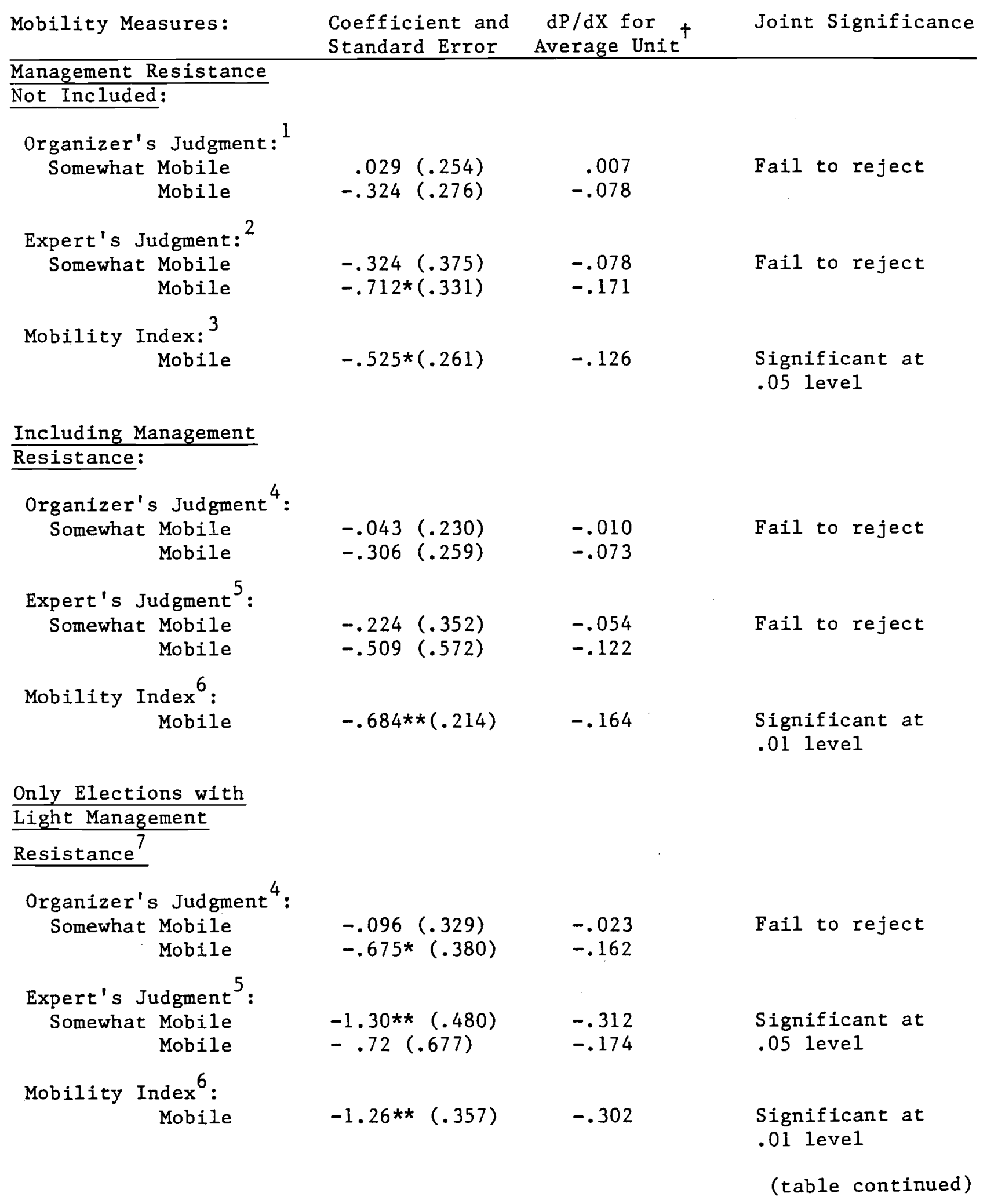


Table 4 continued

significant at .05 level * .01 level **

in one-tail test

\section{Footnotes:}

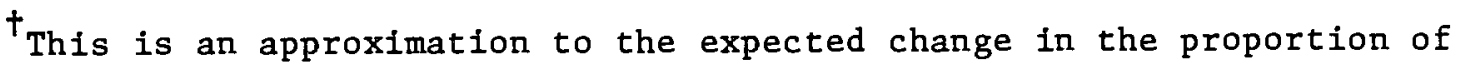
workers voting union in an average unit. It is constructed by multiplying the coefficient times the average proportion voting union times one minus that proportion.

1. Control variables in equation after removal of those units with $t$ statistics < 1 are: percent Chicano, more than 10 locations, teamsters, communications, some computer work, clericals do work for other offices, clericals do inventory work, utility, clericals do phone work, clericals operate switchboard.

2. Control variables in equation after removal of those with $t$ statistics < 1 are: more than 10 locations, CWA, communications industry, clericals do some computer work, clericals do work for more than one office, clericals do inventory work, utility, clericals do phone work, clericals operate switchboard.

3. Control variables in equation after removal of those with $t$ statistics < 1 are: percent Chicano, more than 10 locations, teamsters, communications industry, clericals do some computer work, clericals do work for other offices, clericals do inventory work, utility, clericals do phone work, clericals operate switchboard.

4. Control variables in equation after removing those units with $t$ statistics < 1 are: percent Chicano, more than 10 other locations, ILWU, communications industry, clericals do some computer work, clericals do inventory work, utility, clericals do phone work, clericals operate switchboard, and two dummy variables for elections with normal and intense management resistance.

5. Control variables in equation after removing those with $t$ statistics $<1$ are: percent Chicano, year, more than 10 locations, teamsters, CWA, trucking industry, communications industry, utility, clericals do some computer work, clericals do some work for other offices, clericals do inventory work, clericals do phone work, clericals operate switchboard, and two dummy variables for elections with normal and intense management resistance.

6. Control variables in equation after removing those with $t$ statistics < 1 are: percent Chicano, more than 10 other locations, teamsters, utility, clericals do some computer work, clericals do work for other offices, clericals do inventory work, clericals do phone work, clericals operate switchboard, and two dummy variables for elections with normal and intense management resistance.

7. Specifications are the same as those above except that the management resistance dummies were interacted with the mobility measure. Only the coefficients for mobility when resistance was light are reported. 


\section{Appendix 1 \\ Questionnaire Used to Validate Mobility Measures}

At your workplace an election for union representation was held. As office workers you were able to vote in the election. Regardless of how you voted, please evaluate how the following factors influenced your decision to vote for or against the union (or not to vote at a11). YOUR ANSWERS ARE COMPLETELY CONFIDENTIAL.

For each question, please circle the number that best describes how important each factor was in your decision to vote for or against union representation.

Very Somewhat Not too Not at all

A. Your pay at the time of the election. : : + . . . . 1

B. The information provided by union supporters about the union. 1

2

3

4

C. The union dues you would have to

pay if the union won. ...... 1

2

3

4

D. The concern that your employer

may have your job done at a

different location if the

union won .......... 1

3

4

E. Your present relationship

with management........ . 1

3

4

F. Your opportunities for job

training or promotion at

your present job. . . . . . 1

23

4

G. The possibility of a strike

if the union won. . . . . . . . 1

2

3

4

H. The information provided by your employer about the union . . 1

3

4

I. The computerization of office work/word processing. . . . . 1

2

3

4

$\mathrm{J}$. The amount of influence you had on decisions affecting your work. 1

2

For Against

12

3

$\mathrm{K}$. How did you vote in the union representation election?

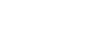

L. Please list other factors that influenced your decision. 
Appendix 2

Estimation Technique

One standard approach to estimating models where the dependent variable is a proportion is to assume that the expected value for the proportion for each observation $p_{i}$ is a logistic function of observed variables $x_{i}$ or

(1)

$$
p_{i}=\frac{1}{1+e^{-X_{i} \beta}}
$$

Designating the size of each group $i$ as $N_{i}$ and the actual proportion as $\hat{\mathrm{p}}_{i}$, if we assume that $\mathrm{N}_{i} \hat{\mathrm{p}}_{i}$ is a binomially distributed random variable with expected value $p_{i} N_{i}$ then the $B s$ of (1) can be consistently estimated by regressing $\log \left(\hat{p}_{i} /\left(1-\hat{p}_{i}\right)\right)$ on the $x_{i} s$ and can be efficiently estimated if the variables are all weighted by an appropriate approximation to the variance of the random variable

$$
v_{i}=\log \left(\hat{p}_{i} /\left(1-\hat{p}_{i}\right)\right)-\log \left(p_{i} /\left(1-p_{i}\right)\right)
$$

This is the method of Minimum Chi-Squared Logit. 
There are two problems with this as an approach to the data used here. First some of the $p_{i} s$ are equal to one or zero so that the standard logit transformation is undefined. This problem is remedied by adopting the alternative transformation proposed by Haldane,

$$
L_{i}=\log \left(\left(p_{i}+\frac{1}{2 N_{i}}\right) /\left(1-p_{i}+\frac{1}{2 N_{i}}\right)\right)=x_{i} \beta .
$$

The second problem is that both logit transformations assume that all attributes of an election unit which determine the probability of a worker voting union are observed. This is certainly not the case. To solve this problem we augment the Haldane model by assuming

$$
L_{i}=x_{i}^{\beta}+\gamma_{i}
$$

where $\gamma_{i}$ is an unobserved i.i.d. error term. Dickens [1985] shows that this model can be efficiently estimated using a 2-step procedure. In the first step consistent estimates of the $\beta s$ and the variance of the $\gamma_{i}$ are obtained. Weighted estimation is done in the second step to obtain efficient estimates. 